\title{
Evaluation of vestibular and oculomotor functions in individuals with dizziness after stroke
}

\author{
Avaliação das funções vestibular e oculomotora em indivíduos com tontura após acidente \\ vascular encefálico
}

\author{
Bianca Nunes Pimentel', Valdete Alves Valentins dos Santos Filha ${ }^{1}$
}

\begin{abstract}
Changes in postural balance and visual complaints are frequent consequences of stroke. We aimed to investigate the symptoms and the vestibular and oculomotor functions of patients with dizziness post ischemic and hemorrhagic stroke and compare the results among them. Methods: Fifty patients with dizziness after stroke were evaluated through a clinical anamnesis and computerized vector electronystagmography: calibration of ocular movements, spontaneous nystagmus, semi-spontaneous nystagmus, pendular tracking, optokinetic nystagmus, rotary chair testing, and the caloric test. Results: All patients complained of dizziness, especially imbalance. Ischemic stroke in the carotid territory was the prevalent type. Visual complaints were reported by $56 \%$ of the sample and were related to abnormalities in oculomotor and caloric tests. Conclusion: The occurrence of visual symptoms was related to some abnormalities in the vector electronystagmography tests, being more frequent in cases of stroke in the vertebrobasilar system, and with oscillopsia and reduced visual acuity as symptoms.
\end{abstract}

Keywords: Stroke; dizziness; vestibular function tests; vision disorders.

\section{RESUMO}

Alterações no equilíbrio postural são consequências frequentes no acidente vascular cerebral (AVC). O objetivo deste estudo foi investigar os sintomas e as funções vestibular e oculomotora de sujeitos com tontura após AVC isquêmico e hemorrágico, comparando seus resultados. Métodos: Foram avaliados 50 sujeitos com tontura após AVC, por meio de anamnese clínica e vectoeletronistagmografia computadorizada (VENG): calibração dos movimentos oculares; nistagmo espontâneo e semi-espontâneo; rastreio pendular; nistagmo optocinético; prova rotatória pendular decrescente e prova calórica com estímulo a ar. Resultados: Todos relataram tontura, principalmente do tipo desequilíbrio. O AVC isquêmico e no sistema carotídeo foi o mais frequente. Sintomas visuais pós-AVC foram referidos por $56 \%$ da amostra, os quais tiveram relação com alterações nas provas oculomotoras e calórica da VENG. Conclusão: A ocorrência de sintomas visuais relacionou-se a alterações em alguns testes. Essas alterações foram mais frequentes nos casos de AVC da circulação posterior, naqueles com oscilopsia e diminuição da acuidade visual.

Palavras-chave: Acidente vascular cerebral; tontura; testes de função vestibular; transtornos da visão.

In recent decades, Brazil has undergone a rapid epidemiological transition as a result of a decrease in infectious diseases and an increase in chronic diseases, such as hypertension, diabetes mellitus and obesity. These health conditions are risk factors for the occurrence of serious events such as stroke ${ }^{1}$.

Strokes vary depending on size and site of the tissue damaged by the reduction of blood flow - caused by infarction in ischemic stroke, or by hemorrhage, in hemorrhagic stroke. The most common symptoms are sudden limb or facial weakness, language disorders, impaired vision, strong headache and dizziness. The nature and severity of the sequelae depend on the lesion'.

Body balance is the result of a harmonious interaction between the afferents from sensory systems (vestibular, proprioceptive and visual), thus generating motor responses through precise processing in the central nervous system ${ }^{3}$. The vestibular system includes structures of the inner ear (middle and posterior labyrinth), responsible for sending continuous information about movements and positions of the head and body to integrative centers in the brainstem, cerebellum and somatosensory cortex ${ }^{4}$.

The somatosensory system organizes proprioceptive information, while the visual system provides information about the position of the body in relation to the external environment. When the functions of the sensory triad are disrupted, unpleasant sensations occur, e.g. dizziness, nausea, feeling of imbalance and, sometimes, nystagmus (uncontrollable eye movements). The body's balance is vulnerable to diseases that disrupt the systems or its sensory integration ${ }^{5}$. 
Vestibular testing investigates the vestibular function and its relationship with other systems, as well as the afferent and efferent fibers of the cerebellum, spinal cord and reticular formation of the brainstem ${ }^{6}$. Stroke is one of the most-frequent etiological diagnosis among cases of vestibular symptoms arising from impairment of the central nervous system ${ }^{7}$.

Eye fixation is important for keeping balance in normal situations. After stroke, patients may be even more dependent on fixation while attempting to keep static or dynamic balance $^{8}$. Visual disorders after a stroke may include spontaneous nystagmus ${ }^{9}$, abnormalities in motricity ${ }^{10,11}$ and perception $^{12,13}$, which can affect either one or both eyes ${ }^{14}$. These disorders have a strong impact on the daily lives of the individuals affected, who are not provided with enough regular support or given sufficient information about visual problems after a stroke event ${ }^{15}$.

Therefore, the aim of the present study was to investigate the vestibular and the oculomotor functions of patients with dizziness after an ischemic stroke and a hemorrhagic stroke in the chronic phase, as well as compare the results with vestibular and visual symptoms.

\section{METHODS}

This was an observational, cross-sectional study with quantitative analysis, registered and approved by a Research and Ethics Committee under the Certificate of Presentation for Ethical Consideration protocol number 16728013.0.0000.5346.

The sample comprised patients referred to the Otoneurology Outpatient Clinic, Department of Postural Balance, of a university hospital. The following inclusion criteria were taken into account: having had an ischemic stroke or a hemorrhagic stroke at least 30 days prior to data collection, regardless of complaint of dizziness; being 18 years of age or older; psychologically and medically stable.

Patients were excluded if they had a history of visual impairments - either congenital or acquired before the occurrence of stroke (two patients had strabismus and bilateral visual impairment), were bedridden or wheelchair users (six patients), or quit the evaluation (two patients), which resulted in 10 exclusions. Thus, a total of 50 patients were included in the sample. They agreed to participate in the research by reading and signing an informed consent form.

\section{Procedures}

The participants followed a few guidelines, which were essential for the test: 1) avoiding the intake of substances that could affect the labyrinth (caffeine, chocolate, alcohol) and/or narcotics, for 24 hours prior to the test; 2) avoiding the use of central nervous system depressants for 48 hours; 3) having a light meal three hours before the examination; 4) avoiding the use of contact lenses; 5) not wearing make-up, to facilitate electrical conductivity ${ }^{6}$.

All patients answered a structured interview to collect data on their prior and current clinical history, with questions about stroke, the presence and characteristics of dizziness, as well as possible comorbidities.

Their external acoustic meatus and tympanic membrane were visually checked with a Heine otoscope for possible obstructions that could prevent the application of caloric testing with water irrigation.

A Contronic SCV vector electronystagmography system (version 5.0) was used; the light bar was positioned one meter toward the midline of the eyes. The test was performed in a quiet room with low light. The patient's skin was cleaned for attachment of four electrode patches, with electrolytic paste and micropore adhesive tape, on the periorbital region - corner of the eyes, on the frontal region (ground), and the last electrode two centimeters above the glabella (active), allowing for the recording of horizontal, vertical and oblique eye movements.

Oculomotor testing was then performed to assess: 1) calibration of horizontal and vertical eye movements: the light points were moved alternately, with movement equivalent to $10^{\circ}$ gaze deviation. Speed was $10 \mathrm{~mm} / \mathrm{s}$; 2) spontaneous nystagmus with eyes open, and then closed; 3) semi-spontaneous nystagmus; 4) pendular tracking, which allows for visualization of a sinusoidal curve of eye movement; 5) optokinetic nystagmus, visual tracking of light points moving to the right and then to the left.

Afterwards, vestibular testing was performed using: 1) the rotary chair test, which allows the evaluation of pairs of synergistic lateral semicircular canals. The patient's head was positioned at a $30^{\circ}$ angle, with eyes closed, during the pendular movement of the rotating chair; 2) caloric test, with water irrigation $(240 \mathrm{ml})$ for 40 seconds at temperatures of $44^{\circ} \mathrm{C}$ and $30^{\circ} \mathrm{C}$, in the following sequence: $44^{\circ} \mathrm{C}$ - right ear, $44^{\circ} \mathrm{C}$ left ear, $30^{\circ} \mathrm{C}$ - right ear and $30^{\circ} \mathrm{C}$ - left ear; with a three-minute interval between the tests ${ }^{16}$. The patients were positioned in a supine position, at a $30^{\circ}$ angle to the horizontal plane (position I of Brünings).

To record post-caloric nystagmus, the patients kept their eyes closed and performed a mental task in order to maximize vestibulo-ocular reflex responses. Afterwards, the patients were instructed to open their eyes and fix them on one point to check for the presence of the eye fixation offset effect ${ }^{6}$.

\section{Statistical analysis}

Dichotomous variables were created to identify the responses of nominal variables, for example present/absent, while considering: the presence of spontaneous nystagmus with eyes closed and angular velocity of the slow component greater than $7^{\circ} / \mathrm{s}$; directional preponderance of nystagmus with asymmetry greater than $30 \%$ (relative values) for the 
rotary chair and caloric tests, and for the absolute values of the latter test, angular speed of less than $3^{\circ} / \mathrm{s}$ or greater than $50^{\circ} / \mathrm{s}^{16}$.

Absolute and relative frequencies were calculated for the categorical variables. To check for normality of quantitative variables, the Shapiro-Wilk test was used. The association between independent variables and the presence of visual abnormalities were determined with the Chi-square test of association or Fisher's Exact test (when at least one of the expected frequencies was less than 5) while the MannWhitney $U$ test was used for the ordinal or continuous variables without a normal distribution. For all statistical tests, the software Statistica 9.1 was used, with a level of significance of $5 \%$, i.e., results were statistically significant when $\mathrm{p}$ $\leq 0.05$.

\section{RESULTS}

The present study had 50 patients, 25 (50\%) males and $25(50 \%)$ females, with a mean age of 63.24 years $( \pm 10.61)$, between 42 and 85 years. All of them complained of dizziness as a sequela of stroke.

The prevalent types of dizziness were: imbalance (41$82 \%)$, followed by vertigo (9-18\%) - eight $(88.89 \%)$ of whom had the subjective type and one (11.11\%) had objective vertigo. Ischemic stroke was more frequent (42-84\%) than hemorrhagic stroke (8-16\%); 45 (90\%) of the strokes occurred in the carotid territory, four (8\%) in the vertebrobasilar territory, and one $(2 \%)$ in both. There was a relationship between hemorrhagic stroke and the presence of spontaneous nystagmus, 12 of which (24\%) had an angular speed of the slow component > $7^{\circ} / \mathrm{s}$ (abnormal). Among the 16 cases of vestibular dysfunction, eight (50\%) were due to hyperreflexia, four (25\%) to directional preponderance of nystagmus and four (25\%) to labyrinthine preponderance. The average asymmetry index in the optokinetic nystagmus was $14.9 \%$ ( \pm 14.51 ), ranging from $2 \%$ to $67 \%$, with a normal level up to $20 \%$. The average asymmetry index in the rotary chair test was $11.54 \%( \pm 7.87)$, ranging from $2 \%$ to $37 \%$, with a normal level up to $30 \%$ (Table 1 ).

In the vector electronystagmography, there was a high incidence of abnormalities in the oculomotor tests, particularly in vertical pendular tracking, as well as 35\% of abnormalities in the patients who completed the caloric test (Table 2 ). In addition, four ( $8 \%$ ) patients did not complete the test at $30^{\circ} \mathrm{C}$ because they felt discomfort (emesis), hence they could only tolerate the test at $44^{\circ} \mathrm{C}$. The measures of angular speed of the slow component, in these irrigations, were lower than $50^{\circ} / \mathrm{s}$.

There was no relationship between the type of dizziness (vertigo or imbalance) and the location of (anterior or posterior) circulation impairment ( $\mathrm{p}=0.54)$.

Twenty-eight (56\%) presented with some visual symptom (Figure).

The mean symmetry index, in the caloric test, was based on the relative values; in the group with visual complaints, it was $11.93 \%( \pm 7.41)$ while in the group without visual complaints it was $11.04 \%$ ( \pm 8.58). Visual disorders caused by directional preponderance of nystagmus had a mean of $35 \%$ $( \pm 2.45)$, while dysfunction caused by labyrinthine preponderance had a mean of $44 \%( \pm 9.90)$. The group without visual disorders had a mean of $10.67( \pm 8.19)$ (Table 3$)$.

Table 1. Distribution of results found in computer-aided vector electronystagmography for the total sample $(n=50)$.

\begin{tabular}{|c|c|}
\hline Computer-aided vector electronystagmography & Tests \\
\hline \multirow{2}{*}{ Horizontal calibration } & Regular \\
\hline & Irregular \\
\hline \multirow{2}{*}{ Vertical calibration } & Regular \\
\hline & Irregular \\
\hline \multirow{2}{*}{ Spontaneous nystagmus - eyes open } & Absent \\
\hline & Present \\
\hline \multirow{2}{*}{ Spontaneous nystagmus - eyes closed } & Absent \\
\hline & Present \\
\hline \multirow{2}{*}{ Semi-spontaneous nystagmus } & Absent \\
\hline & Present \\
\hline \multirow{2}{*}{ Horizontal pendular tracking } & Type I/II \\
\hline & Type III/IV \\
\hline \multirow{2}{*}{ Vertical pendular tracking } & Type I/II \\
\hline & Type III/IV \\
\hline \multirow{2}{*}{ Optokinetic nystagmus } & Symmetrical \\
\hline & Asymmetrical \\
\hline \multirow{2}{*}{ Rotary chair testing } & Symmetrical \\
\hline & Asymmetrical \\
\hline \multirow{2}{*}{ Caloric testing $(n=46)$} & Normal \\
\hline & Abnormal \\
\hline
\end{tabular}


Table 2. Distribution of results found in computer-aided vector electronystagmography vectoelectronystagmography (VENG) for the ischemic stroke and hemorrhagic stroke groups $(n=50)$.

\begin{tabular}{|c|c|c|c|c|}
\hline $\begin{array}{l}\text { Computer-aided vector } \\
\text { electronystagmography }\end{array}$ & Tests & Ischemic stroke - n (\%) & Hemorrhagic stroke - n (\%) & $p$-value \\
\hline \multirow{2}{*}{ Horizontal calibration } & Regular & $36(85.71)$ & $07(87.50)$ & \multirow{2}{*}{0.69} \\
\hline & Irregular & $06(14.29)$ & $01(12.50)$ & \\
\hline \multirow{2}{*}{ Vertical calibration } & Regular & $30(71.43)$ & $07(87.50)$ & \multirow{2}{*}{0.32} \\
\hline & Irregular & $12(28.57)$ & $01(12.50)$ & \\
\hline \multirow{2}{*}{ Spontaneous nystagmus - eyes open } & Absent & $40(95.24)$ & $07(87.50)$ & \multirow{2}{*}{0.41} \\
\hline & Present & $02(4.76)$ & $01(12.50)$ & \\
\hline \multirow{2}{*}{ Spontaneous nystagmus - eyes closed } & Absent & $31(73.81)$ & $02(25.00)$ & \multirow{2}{*}{$0.01 *$} \\
\hline & Present & $11(26.19)$ & $06(75.00)$ & \\
\hline \multirow{2}{*}{ Semi-spontaneous nystagmus } & Absent & $36(85.71)$ & $06(75.00)$ & \multirow{2}{*}{0.38} \\
\hline & Present & $06(14.29)$ & $02(25.00)$ & \\
\hline \multirow{2}{*}{ Horizontal pendular tracking } & Type I/II & 34 (80.95) & $06(75.00)$ & \multirow{2}{*}{0.51} \\
\hline & Type III/IV & $08(19.05)$ & $02(25.00)$ & \\
\hline \multirow{2}{*}{ Vertical pendular tracking } & Type I/II & $25(59.52)$ & $03(37.50)$ & \multirow{2}{*}{0.22} \\
\hline & Type III/IV & $17(40.48)$ & $05(62.50)$ & \\
\hline \multirow{2}{*}{ Optokinetic nystagmus } & Symmetrical & $30(71.43)$ & $06(75.00)$ & \multirow{2}{*}{0.60} \\
\hline & Asymmetrical & $12(28.57)$ & $02(25.00)$ & \\
\hline \multirow{2}{*}{ Rotary chair testing } & Symmetrical & $41(97.62)$ & $08(100)$ & \multirow{2}{*}{0.84} \\
\hline & Asymmetrical & $01(2.38)$ & $00(0)$ & \\
\hline \multirow{2}{*}{ Caloric test $(n=46)$} & Normal & $26(61.90)$ & $04(50.00)$ & \multirow{2}{*}{0.27} \\
\hline & Abnormal & $12(38.10)$ & $04(50.00)$ & \\
\hline
\end{tabular}

IS: Ischemic stroke; HS: hemorrhagic stroke; n: absolute frequency; (\%): relative frequency; EO: eyes open; EC: eyes closed; (-): absent; (+): present; MannWhitney $\cup$ test, $p \leq 0.05$

Visual symptoms $(n=50)$

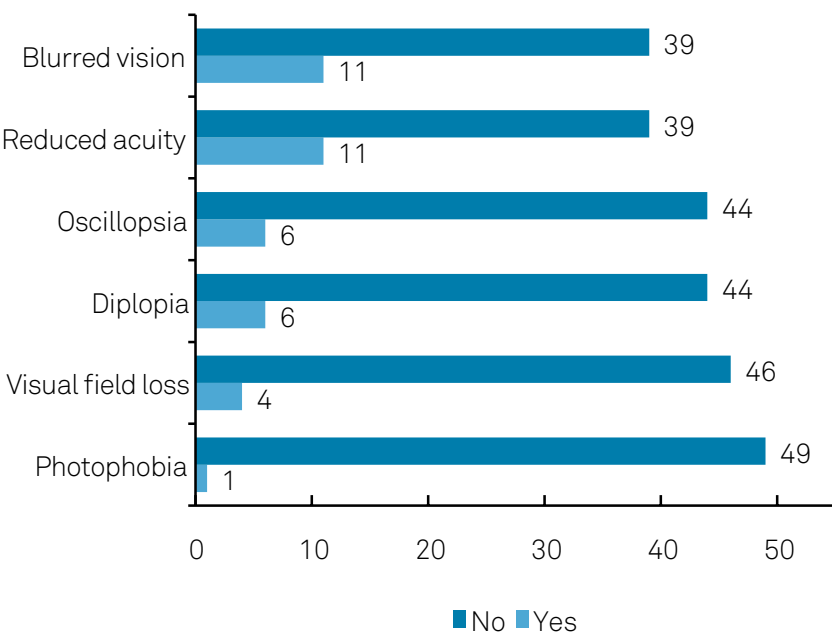

Values expressed in number of individuals.

Figure. Frequency of visual abnormalities in individuals affected by stroke in the chronic phase $(n=50)$.

The presence of abnormalities in the oculomotor tests was related to posterior circulation stroke $(\mathrm{p}=0.028)$ and to oscillopsia (Table 4). Regarding the use of corrective lenses, $35(70 \%)$ patients used them, but $20(57.14 \%)$ reported not having fully adapted to them.

\section{DISCUSSION}

The sixth decade of life is the one with the primary occurrence of cerebrovascular diseases ${ }^{17}$. The association between the natural process of aging and abnormalities determined by bad lifestyle habits may trigger the process of senility ${ }^{18}$, marked by the presence of chronic diseases, which are risk factors for stroke. Ischemic stroke was more common than hemorrhagic stroke, in agreement with the literature, which consistently reports a percentage of around $85 \%$ for ischemic stroke, $10 \%$ for hemorrhagic stroke and $5 \%$ for transient ischemic attacks ${ }^{19}$.

The most common type of dizziness was imbalance, as described as dizziness triggered by central causes ${ }^{7}$. This corresponds to approximately $15 \%$ of the complaints of body balance disorders ${ }^{20}$; however, unlike vertigo, imbalance suggests a neurological etiology ${ }^{21}$, which explains its high occurrence in this sample.

Although the relationship between vestibular symptoms and posterior stroke is frequently reported in the literature, there are reports of vestibular dysfunction, with vertigo and nystagmus, caused by middle cerebral artery infarction ${ }^{22}$. The typical sites are the insula, parietal cortex and adjacent subcortical white matter. Thus, dizziness cannot be considered a rare manifestation in carotid territory strokes, particularly in the temporoparietal regions ${ }^{23}$. 
The calibration of eye movements, even in those tracings that were evaluated as regular, were revealed as qualitatively diminished or mildly dysmetric tracking curves, characteristic of a central lesion ${ }^{16}$. As for nystagmus morphology, abnormalities are not evaluated by the software, therefore, visual assessment has to be performed while recording the tracings ${ }^{24}$.

Some patients had the presence of spontaneous nystagmus without vestibular dysfunction. The incidence of spontaneous nystagmus post-stroke ranges between $20 \%$ and $30 \%{ }^{25,26,27}$. Spontaneous nystagmus can result from peripheral lesions of the connections of the CNS or from lesions of the visual system ${ }^{28}$. Spontaneous nystagmus with open eyes, except in periods of crisis, is a pathognomonic sign of a central lesion. Similarly, if spontaneous nystagmus with eyes closed is present, coexisting with symmetry of the vestibular function, this is suggestive of a central abnormality ${ }^{6}$. Four of the six patients with the presence of spontaneous nystagmus with eyes closed had had a posterior stroke. In vascular cases, nystagmus is due mainly to lesions in the brainstem ${ }^{29}$.

The pendular tracking type III and VI have been described in a previous study ${ }^{10}$, in which most of the patients showed no vestibular dysfunction. The authors concluded that patients with a history of carotid territory stroke may have dizziness or body imbalance and signs of impairment of ocular motility and of the vestibular function without dizziness ${ }^{10}$.

Type III horizontal pendular tracking is common in central disorders while type IV is typical of these conditions. On the other hand, types III and IV occurred more often in vertical tracking, which suggests that the latter is more sensitive for detecting abnormal eye movements ${ }^{6.30}$. A normal pattern of pursuit eye movements can be recorded if there is functional integrity of the neural pathways of the brainstem. However, patients with stroke, caused by possible lesions in the region of the brainstem or the cerebellum, may fail to make accurate pursuit eye movements toward the visual target $^{28}$. The presence of compensatory saccades while tracking may be related to abnormalities in the striate cortex, brainstem and cerebellum. When they are unilateral, they suggest lesions in the occipital, parietal or frontal lobe. Combined disorders in gain and slow phase suggest lesions in the cerebellum or the brainstem ${ }^{31}$.

The abnormal directional preponderance of nystagmus found in the per-rotatory nystagmus occurred in one patient.

Table 3. Distribution of results found in computer-aided vectoelectronystagmography vector electronystagmography (VENG) for the groups without visual symptoms and with visual symptoms $(n=50)$.

\begin{tabular}{|c|c|c|c|c|}
\hline $\begin{array}{l}\text { Computer-aided vector } \\
\text { electronystagmography }\end{array}$ & Test & Without visual symptoms n (\%) & With visual symptoms n (\%) & $p$-value \\
\hline \multirow{2}{*}{ Horizontal calibration } & Regular & $19(86.36)$ & $24(85.71)$ & \multirow{2}{*}{0.63} \\
\hline & Irregular & $03(13.64)$ & $04(14.29)$ & \\
\hline \multirow{2}{*}{ Vertical Calibration } & Regular & $18(81.82)$ & $19(67.86)$ & \multirow{2}{*}{0.22} \\
\hline & Irregular & $04(18.18)$ & $09(32.14)$ & \\
\hline \multirow{2}{*}{ Spontaneous nystagmus - eyes open } & Absent & $22(100.00)$ & $25(89.29)$ & \multirow{2}{*}{0.17} \\
\hline & Present & $00(0)$ & $03(10.71)$ & \\
\hline \multirow{2}{*}{ Spontaneous nystagmus - eyes closed } & Absent & $17(77.27)$ & $16(57.14)$ & \multirow{2}{*}{0.12} \\
\hline & Present & $05(22.73)$ & $12(42.86)$ & \\
\hline \multirow{2}{*}{ Semi-spontaneous nystagmus } & Absent & $18(81.82)$ & $23(82.14)$ & \multirow{2}{*}{0.50} \\
\hline & Present & $04(18.18)$ & $05(17.86)$ & \\
\hline \multirow{2}{*}{ Horizontal pendular tracking } & Type I/II & $21(95.45)$ & $19(67.86)$ & \multirow{2}{*}{0.01} \\
\hline & Type III/IV & $01(4.55)$ & $09(32.14)$ & \\
\hline \multirow{2}{*}{ Vertical pendular tracking } & Type I/II & $15(68.18)$ & $13(46.43)$ & \multirow{2}{*}{0.12} \\
\hline & Type III/IV & $07(31.82)$ & $15(53.57)$ & \\
\hline \multirow{3}{*}{ Optokinetic nystagmus } & Symmetrical & $18(81.82)$ & $20(71.43)$ & \multirow{3}{*}{0.30} \\
\hline & & & & \\
\hline & Asymmetrical & $04(18.18)$ & $08(28.57)$ & \\
\hline \multirow{3}{*}{ Rotary chair testing } & Symmetrical & $21(95.45)$ & $28(100.00)$ & \multirow{3}{*}{0.44} \\
\hline & & & & \\
\hline & Asymmetrical & $01(4.54)$ & $00(0.00)$ & \\
\hline \multirow{2}{*}{ Caloric test (n 46) } & Normal & $17(80.95)$ & $13(52.00)$ & \multirow{2}{*}{0.04} \\
\hline & Abnormal & $04(19.05)$ & $12(48.00)$ & \\
\hline
\end{tabular}

EO: eyes open; EC: eyes closed; $n$ : absolute frequency; \%: relative frequency; $(-)$ : absent; $(+)$ : present. Fisher's exact test, $p \leq 0.05$. 
Table 4. Relationship between percentage (\%) results of oculomotor testing with vector electronystagmography VENG and visual symptoms present (Yes) or absent (No), classified by type $(n=50)$

\begin{tabular}{|c|c|c|c|c|c|c|c|c|c|c|c|c|}
\hline \multicolumn{13}{|c|}{ Computer-aided vector electronystagmography - Tests with light bar } \\
\hline \multirow[t]{2}{*}{ Visual symptoms } & \multicolumn{2}{|c|}{$\begin{array}{c}\text { Spontaneous } \\
\text { nystagmus eyes } \\
\text { open }\end{array}$} & \multicolumn{2}{|c|}{$\begin{array}{c}\text { Spontaneous } \\
\text { nystagmus eyes } \\
\text { closed }\end{array}$} & \multicolumn{2}{|c|}{$\begin{array}{c}\text { Semi- } \\
\text { spontaneous } \\
\text { nystagmus }\end{array}$} & \multicolumn{2}{|c|}{$\begin{array}{c}\text { Pendular tracking } \\
\text {-Horizontal }\end{array}$} & \multicolumn{2}{|c|}{$\begin{array}{c}\text { Pendular tracking } \\
\text { - Vertical }\end{array}$} & \multicolumn{2}{|c|}{$\begin{array}{l}\text { Optokinetic } \\
\text { nystagmus }\end{array}$} \\
\hline & $(-)$ & $(+)$ & $(-)$ & $(+)$ & $(-)$ & $(+)$ & I-II & III-IV & $\mid-I I$ & III-IV & Sym. & Asym. \\
\hline \multicolumn{13}{|l|}{ Blurred vision* } \\
\hline Yes & 100 & 0 & 72.73 & 27.27 & 90.91 & 9.09 & 100 & 0 & 63.64 & 36.36 & 81.82 & 18.18 \\
\hline No & 92.31 & 7.69 & 64.10 & 35.90 & 82.05 & 17.95 & 74.36 & 25.64 & 53.85 & 46.15 & 74.36 & 25.64 \\
\hline$p$-value & \multicolumn{2}{|c|}{0.47} & \multicolumn{2}{|c|}{0.44} & \multicolumn{2}{|c|}{0.43} & \multicolumn{2}{|c|}{0.06} & \multicolumn{2}{|c|}{0.41} & \multicolumn{2}{|c|}{0.47} \\
\hline \multicolumn{13}{|l|}{ Oscillopsia* } \\
\hline Yes & 50 & 50 & 33.33 & 66.67 & 66.67 & 33.33 & 33.33 & 66.67 & 16.67 & 83.33 & 66.67 & 33.33 \\
\hline No & 100 & 0 & 70.45 & 29.55 & 86.36 & 13.64 & 86.36 & 13.64 & 61.36 & 38.64 & 77.27 & 22.73 \\
\hline$p$-value & \multicolumn{2}{|c|}{$0.001 *$} & \multicolumn{2}{|c|}{0.09} & \multicolumn{2}{|c|}{0.24} & \multicolumn{2}{|c|}{$0.01 *$} & \multicolumn{2}{|c|}{$0.05^{*}$} & \multicolumn{2}{|c|}{0.45} \\
\hline \multicolumn{13}{|l|}{ Diplopia* } \\
\hline Yes & 83.33 & 16.67 & 33.33 & 66.67 & 100 & 0 & 50 & 50 & 33.33 & 66.67 & 66.67 & 33.33 \\
\hline No & 95.45 & 4.55 & 70.45 & 29.55 & 81.82 & 18.18 & 84.09 & 15.91 & 59.09 & 40.91 & 77.27 & 22.73 \\
\hline$p$-value & \multicolumn{2}{|c|}{0.32} & \multicolumn{2}{|c|}{0.09} & \multicolumn{2}{|c|}{0.33} & \multicolumn{2}{|c|}{0.08} & \multicolumn{2}{|c|}{0.23} & \multicolumn{2}{|c|}{0.45} \\
\hline Accuracy* & & & & & & & & & & & & \\
\hline Yes & 100 & 0 & 72.73 & 27.27 & 90.91 & 9.09 & 72.73 & 27.27 & 81.82 & 18.18 & 72.73 & 27.27 \\
\hline No & 92.31 & 7.69 & 64.10 & 35.90 & 82.05 & 17.95 & 82.05 & 17.95 & 48.72 & 51.28 & 76.92 & 23.08 \\
\hline$p$-value & & & & & & & & & & & & \\
\hline Photophobia** & & & & & & & & & & & & \\
\hline Yes & 100 & 0 & 0 & 100 & 0 & 100 & 100 & 0 & 0 & 100 & 100 & 0 \\
\hline No & 93.88 & 6.12 & 67.35 & 32.65 & 85.71 & 14.29 & 79.59 & 20.41 & 57.14 & 42.86 & 75.51 & 24.49 \\
\hline$p$-value & & & & & & & & & & & & \\
\hline Visual field** & & & & & & & & & & & & \\
\hline Yes & 100 & 0 & 50 & 50 & 100 & 0 & 75 & 25 & 50 & 50 & 50 & 50 \\
\hline No & 93.48 & 6.52 & 67.39 & 32.61 & 82.61 & 17.39 & 80.43 & 19.57 & 56.52 & 43.48 & 78.26 & 21.74 \\
\hline$p$-value & & & & & & & & & & & & \\
\hline
\end{tabular}

Other authors have also found this low occurrence $(5 \%)^{10}$. Vestibular compensation involves the vestibular nuclei, restoring the activity of its resting potential and reducing the asymmetry between the left and the right nuclei ${ }^{32}$. First, the cerebellum inhibits the activity of the vestibular nuclei contralateral to the lesion by reducing relative hyperactivity. In a second phase, a new intrinsic activity is created in the vestibular nuclei ipsilateral to the lesion, thereby compensating for the ipsilateral $\operatorname{loss}^{33}$. Vestibular decompensation results in dizziness that may last for a short period or up to almost 30 days $^{34}$. Thus, the event is difficult to observe in patients who have chronic sequelae.

Visual perception disorders after stroke may reach a high prevalence ${ }^{12}$. Diplopia, perception of two images of the same object, may occur both in the carotid territory and in vertebrobasilar stroke ${ }^{35-36}$. Causes of diplopia include lesions of cranial nerves or their nuclei and strokes in the cerebellum ${ }^{37}$.

Visual field loss can arise from both anterior and posterior strokes ${ }^{36,38}$ and the occurrence may be as high as $52.3 \%^{39}$. In this sample, only $8 \%$ of patients reported this symptom. These disorders can be treated through training to restore visual function, not only to increase visual field capabilities but also to subjectively improve regular visual functions ${ }^{40}$.
Although there may be spontaneous improvement of lesions, some sequelae may remain chronic. A previous study found a low reduction of abnormalities after 90 days $^{41}$. The patients affected, and their caregivers, need further information to increase their knowledge and awareness of post-stroke visual impairment, because many patients do not have an early visual assessment or treatment for their visual disorders ${ }^{15}$.

Although the labyrinthine preponderance is typically peripheral, the possibility of a central etiology cannot be discarded. The hyperreflexia and abnormal directional preponderance of nystagmus may be related to the presence of spontaneous nystagmus, abnormal vestibular tonus caused by a peripheral lesion, in the vestibular nuclei or in the cerebellum. In hyperreflexia, there have been cases of nystagmus-sensation dissociation, which may indicate central impairment ${ }^{24}$.

Abnormalities in oculomotor tests, analyzed through vector electronystagmography, were not exclusive to the patients with visual complaints (Table 3), partly because oscillopsia and the decrease of visual acuity were only significantly related to abnormalities in one or more tests. In 
a previous study, only $9.6 \%$ of the patients had post-stroke visual complaints, but ocular abnormalities were found in $95.5 \%$ of them ${ }^{17}$. In addition, patients with a history of carotid territory stroke may show signs of impairment of ocular motility and vestibular function even without complaints ${ }^{10}$.

There was a relationship between the presence of abnormality in oculomotor tests and the posterior circulation. The nuclei of the nerves responsible for eye movement are located in this region. The oculomotor nerve (cranial nerve III) is located in the upper portion of the midbrain; the trochlear nerve (IV) is located below the lateral nucleus of the oculomotor nerve, more exactly in the pons; and the abducens (VI) is located in the pons, on the floor of the fourth ventricle ${ }^{42}$. Thus, ocular motricity is vulnerable to diseases that affect this region.

Out of the patients who reported vertigo, $79 \%$ described it as subjective (did not see rotating objects, or there was absence of nystagmus). The perception of motion and the vestibulo-ocular reflex serve distinct functions. The vestibulo-ocular reflex keeps one's gaze fixed on the target, while the perception of motion serves various skills, including awareness of self-motion and orientation in space. Although both follow the same neurophysiological principles, they have distinct anatomical correlates ${ }^{43}$.

Individuals with a cerebellar stroke in the distribution of the medial branch of the posterior inferior cerebellar artery may have impaired perception of motion but normal eye movements. In complaints of vertigo without nystagmus, resulting from focal cerebellar infarction, only a portion of lobule IX was affected, while in the patients with nystagmus, the whole of lobule IX was affected. Thus, one can infer a form of cerebellar stroke, where only the perception of motion is affected, with the absence of objective neurological signs ${ }^{43}$.

Some limitations of this study can be outlined. It should be emphasized that only the symptom was considered, i.e., no objective assessments were performed (Goldmann perimetry, for example). Therefore, the values may be underestimated in the present study. In addition, for future studies we suggest a more homogeneous sample between patients with stroke in the carotid and vertebrobasilar systems to obtain inferential results about the location of the lesion.

In conclusion, there was a high incidence of visual symptoms related to abnormalities in the pendular tracking and caloric tests. The abnormalities in the oculomotor tests were more frequent in strokes in the vertebrobasilar region and in patients with oscillopsia and reduced visual acuity. Many patients with visual symptoms did not present with alterations in vector electronystagmography, even in the oculomotor tests. Therefore, other complementary evaluations are important in this population, such as posturography, or even ophthalmologic evaluations, to demarcate the topodiagnosis, thus facilitating the therapeutic actions for these populations.

\section{References}

1. Schmidt MI, Duncan BB, Azevedo e Silva G, Menezes AM, Monteiro CA, Barreto SM et al. Chronic non-communicable diseases in Brazil: burden and current challenges. Lancet. 2011 Jun;377(9781):1949-61. https://doi.org/10.1016/S0140-6736(11)60135-9

2. Sist B, Jesudasan SJ, Winship IR. Diaschisis, degeneration, and adaptive plasticity after focal ischemic stroke in acute ischemic stroke. In: Garci Rodriguez JC. Acute ischemic stroke. IntechOpen. 2012 [acess year month day]. Available from: https://www.intechopen.com/books/acute-ischemic-stroke

3. Lundy-Ekman L. Neurociência: fundamentos para reabilitação. 3a ed. Rio de Janeiro: Elsevier; 2008.

4. Bear MF, Connors BW, Paradiso MA. Neurociências: desvendando o sistema nervoso. 3a ed. Porto Alegre. ArtMed; 2008.

5. Pfeiffer $\mathrm{C}$, Serino A, Blanke O. The vestibular system: a spatial reference for bodily self-consciousness. Front Integr Nuerosci. 2014 Apr;8(31):31. https://doi.org/10.3389/fnint.2014.00031

6. Mor R, Fragoso M. Vestibulometria na prática fonoaudiológica. São Paulo: Pulso; 2012. Capítulo 5, Título do capítulo; p. 43-96.

7. Ganança FF, Fukujima MM, Duarte JA, Bezerra KC, Alves NS, Jomori $R$ et al. Sinais e sintomas vestibulares e doenças do sistema nervoso central. Rev. Equilíbrio Corporal Saúde. 2016;8(1):33-40. https://doi. org/10.17921/2176-9524.2016v8n1p33-40

8. Aoki O, Otani Y, Morishita S, Domen K. The effects of various visual conditions on trunk control during ambulation in chronic post stroke patients. Gait Posture. 2017 Feb;52:301-7. https://doi.org/10.1016/j.gaitpost.2016.12.018
9. Kim MB, Boo SH, Ban JH. Nystagmus-based approach to vertebrobasilar stroke presenting as vertigo without initial neurologic signs. Eur Neurol. 2013;70(5-6):322-8. https://doi.org/10.1159/000353285

10. Pires AP, Fukujima MM, Ganança FF, Aquino LM, Ganança MM, Caovilla $\mathrm{HH}$. Vestibular function in carotid territory stroke patients. Braz J Otorhinolaryngol. 2013 Jan-Feb;79(1):22-7.

11. Collins N, al-Kalbani M, Walsh S, Martin M, Boyle G, Harbison J et al. Ocular microtremor in acute stroke. Ir J Med Sci. 2015;184(10):S423-73.

12. Beaudoin AJ, Fournier B, Julien-Caron L, Moleski L, Simard J, Mercier L et al. Visuoperceptual deficits and participation in older adults after stroke. Aust Occup Ther J. 2013 Aug;60(4):260-6. https://doi.org/10.1111/1440-1630.12046

13. Beasley IG, Davies LN. Visual stress symptoms secondary to stroke alleviated with spectral filters and precision tinted ophthalmic lenses: a case report. Clin Exp Optom. 2013 Jan;96(1):117-20. https://doi.org/10.1111/j.1444-0938.2012.00794.x

14. Siong KH, Woo GC, Chan DY, Chung KY, Li LS, Cheung HK et al. Prevalence of visual problems among stroke survivors in Hong Kong Chinese. Clin Exp Optom. 2014 Sep;97(5):433-41. https://doi.org/10.1111/cxo.12166

15. Rowe FJ. 2015 Views of stroke survivors on impact of visual impairment. Invest Ophthalmol Vis Sci. 2015 Jun;(56):498.

16. Ganança MM, Albernaz PLM, Campos CAH, Souza DG, Ajzental L. Exame labiríntico. In: Albernaz PLM, Ganança MM. Vertigem: estudo clínico da função labiríntica. 2a ed. São Paulo: Moderna; 1976. p. 51-5. 
17. Olubor OJ, Uhumwangho OM, Omoti AE. Ocular disorders in stroke patients in a tertiary hospital in Nigeria. Niger J Clin Pract. 2016 MayJun;19(3):397-400. https://doi.org/10.4103/1119-3077.179290

18. Curiati JAE, Kasai JYT, Nónbrega TCM. Capítulo 2. In: Filho WJ, Kikuchi EL. Geriatria e gerontologia básicas. Rio de Janeiro: Elsevier; 2011. p. 12-4.

19. American Heart Association - AHA. Heart disease and stroke statistics - 2016 Update: a report from the American Heart Association. Circulation. 2015;133:e38-360.

20. Gonçalves DU, Ganança FF, Bottino MA, Greters ME. Manifestações clínicas. In: Mezzalira R, Bittar RSM, Albertino S. Otoneurologia clínica. Rio de Janeiro: Revinter, 2014. p. 129.

21. Drachman DA, Hart CW. An approach to the dizzy patient. Neurology. 1972 Apr;22(4):323-34. https://doi.org/10.1212/WNL.22.4.323

22. von Brevern M, Süßmilch S, Zeise D. Acute vertigo due to hemispheric stroke: a case report and comprehensive review of the literature. J Neurol Sci. 2014 Apr;339(1-2):153-6. https://doi.org/10.1016/j.jns.2014.02.005

23. Zhou Y, Lee S-H, Mantokoudis G, Tehnarni AS, Ying S, Kerber Ket al. Vertigo and Dizziness in anterior circulation cerebrovascular disease: a systematic review. Neurology. 2014;82(10 Supplement): P3.092.

24. Gonçalves DU, Ganança FF, Bottino MA, Greters ME. Avaliação clínica. In: Mezzalira R, Bittar RSM, Albertino S. Otoneurologia clínica. Rio de Janeiro: Revinter, 2014. p. 63

25. Searls DE, Pazdera L, Korbel E, Vysata O, Caplan LR. Symptoms and signs of posterior circulation ischemia in the new England medical center posterior circulation registry. Arch Neurol. 2012 Mar;69(3):346-51. https://doi.org/10.1001/archneurol.2011.2083

26. Su $\mathrm{CH}$, Young YH. Clinical significance of pathological eye movements in diagnosing posterior fossa stroke. Acta Otolaryngol. 2013 Sep;133(9):916-23. https://doi.org/10.3109/00016489.2013.783716

27. Baier B, Müller N, Rhode F, Dieterich M. Vestibular compensation in cerebellar stroke patients. Eur J Neurol. 2015 Feb;22(2):416-8. https://doi.org/10.1111/ene.12475

28. Carmo PC. Vestibulogia II. Porto: Escola Superior de Tecnologia de Saúde do Porto; 2011.

29. Man BL, Fu YP. Acute esotropia, convergence-retraction nystagmus and contraversive ocular tilt reaction from a paramedian thalamomesencephalic infarct. BMJ Case Rep. 2014 Jun;2014 jun11 2:bcr2014205168. https://doi.org/10.1136/bcr-2014-205168

30. Rebelo SM, Castro HD, Ito YI, Caovilla HH, Ganança MM, Albernaz PL et al. Rastreio pendular em síndromes vestibulares periféricas e centrais à vecto-electronistagmografia. Acta AWHO. 1985;4(4):205-10.
31. Gonçalves DU, Ganança FF, Bottino MA, Greters ME. Avaliação clínica. In: Mezzalira R, Bittar RSM, Albertino S. Otoneurologia clínica. Rio de Janeiro: Revinter, 2014. p. 56-7.

32. Kandel ER, Schwartz JH, Jessell TM. The vestibular system. In Kandel ER, Schwartz JH, Jessell TM. Principles of neural science. 4th ed. New York: McGraw-Hill;. 2000. p. 801-15.

33. Young LR, Henn VS. Selective habituation of vestibular nystagmus by visual stimulation. Acta Otolaryngol. 1974 Mar;77(3):159-66. https://doi.org/10.3109/00016487409124612

34. Gonçalves DU, Ganança FF, Bottino MA, Greters ME. Anatomofisiologia vestibular. In: Mezzalira R, Bittar RSM, Albertino S. Otoneurologia clínica. Rio de Janeiro: Revinter, 2014. p. 25.

35. Rowe F; VIS Group UK. Prevalence of ocular motor cranial nerve palsy and associations following Stroke. (Eye 25, p, 881-887, 2011). Int J Stroke. 2011;6(5):404-11. https://doi.org/10.1111/j.1747-4949.2011.00583.x

36. Tao WD, Liu M, Fisher M, Wang DR, Li J, Furie KL, et al. Posterior versus anterior circulation infarction: how different are the neurological deficits? Stroke. 2012 Aug;43(8):2060-5. https://doi.org/10.1161/STROKEAHA.112.652420

37. Desai K, Bullock T, Damani R, Bershad E. Vertical upbeat nystagmus with isolated acute middle cerebellar peduncle stroke. Video J Neurol. 2016;1:1-4. https://doi.org/10.5348/VNP01-2016-1-CV-1

38. Lee $\mathrm{SH}, \mathrm{Kim}$ JS. Acute diagnosis and management of stroke presenting Dizziness or Vertigo. Neurol Clin. 2015 Aug;33(3):687-98. https://doi.org/10.1016/j.ncl.2015.04.006

39. Rowe FJ, Wright D, Brand D, Jackson C, Harrison S, Maan T et al. A prospective profile of visual field loss following stroke: prevalence, type, rehabilitation, and outcome. BioMed Res Int. 2013;2013:719096. https://doi.org/10.1155/2013/719096

40. Bergsma D, Baars-Elsinga A, Sibbel J, Lubbers P, Visser-Meily A. Visual daily functioning of chronic stroke patients assessed by goal attainment scaling after visual restorative training: an explorative study. Top Stroke Rehabil. 2014 Sep-Oct;21(5):400-12.

41. Ali M, Hazelton C, Lyden P, Pollock A, Brady M. Recovery from poststroke visual impairment: evidence from a clinical trials resource. Neurorehabil Neural Repair. 2013 Feb;27(2):133-41. https://doi.org/10.1177/1545968312454683

42. Quiros PA, Yee RD. Myron Yanoff; Jay S. Duker. Oftalmologia. 3rd ed. Rio de Janeiro: Elsevier; 2011. p. 1040.

43. Shaikh AG. Motion perception without Nystagmus: novel manifestation of cerebellar stroke. J Stroke Cerebrovasc Dis. 2014 May-Jun;23(5):1148-56. https://doi.org/10.1016/j.jstrokecerebrovasdis.2013.10.005 